\title{
Green approach to corrosion inhibition effect of Vitex negundo leaf extract on aluminum and copper metals in biodiesel and its blend
}

\author{
B.N. Subedi, K. Amgain, S. Joshi* and J. Bhattarai* \\ Central Department of Chemistry, Tribhuvan University, Kathmandu, Nepal \\ *E-mail: bhattarai 05@yahoo.com; susanjoshi68@gmail.com
}

\begin{abstract}
The corrosion inhibition effect of Nepalese origin plant of Vitex negundo leaf extract on the passivation behavior of aluminum and copper was studied in pure biodiesel (B100) produced from waste cooking oil and its $10 \%$ blend with $90 \%$ petrodiesel $(\mathrm{B} 10)$ at $25 \pm 2^{\circ} \mathrm{C}$ in airtight glass bottle using immersion tests, inhibition efficiency and anodic polarization measurements. The corrosion rate of the aluminum and copper metals was decreased with increasing the concentrations of the methanolic fraction of the plant extract up to $2000 \mathrm{ppm}$ in both the B100 and B10 biofuels. The V. negundo extract showed the maximum corrosion inhibition efficiency of about $83 \%$ in both B100 and B10 for aluminum metal and its maximum inhibition efficiency for copper metal was found about $96 \%$ and $60 \%$ in B100 and $\mathrm{B} 10$, respectively. The phenomena of such high corrosion inhibition action of $V$. negundo plant extract to aluminum and copper metals in both B100 and B10 is mostly explained by the adsorption process of the plant extract on the surface of both metals which obeyed the Langmuir adsorption isotherm. It was found that additions of different concentrations of plant extracts in both B100 and B10 acted as mixed and anodic type corrosion inhibitor for copper and aluminum, respectively, based on the results of immersion and polarization tests. Consequently, it can be said that the $V$. negundo leaf extract can be used as an efficient and environmentally friendly corrosion inhibitor so as to control the corrosion of copper significantly in pure biodiesel as compared to aluminum in B100 and B10 as well as to copper in B10 at room temperature in airtight condition.
\end{abstract}

Keywords: Vitex negundo extract, green inhibitor, aluminum, copper, biodiesel and its blend.

Received: April 12, 2019. Published: September 24, 2019

doi: $\underline{10.17675 / 2305-6894-2019-8-3-21}$

\section{Introduction}

In recent years, it becomes a prime policy of the production and usages of different renewable energy sources of biofuels like biodiesel, bioethanol and their blends even in Nepal, because of their advantages over the conventional non-renewable energy sources of petroleum products. These biofuels have high potential to replace of the petroleum products completely or partially, because they have very close properties to that of the 
petroleum products and have also some technical advantages of the environmentally friendly $[1,2]$. However, exposure of various metallic to biofuels besides petroleum products is one of the high risk areas, where corrosion is most significantly occurred but least studied risk factors. The biofuels and their blends are generally more corrosive than the petroleum products to different metallic materials used particularly in transportation engine, other parts of vehicle, fuel storage systems and so on [3-12]. Therefore, it is one of the important aspects for the study of the corrosive nature of these biofuels to different metallic materials like aluminum, copper, iron metals and their alloys those are generally used as important parts of transportation vehicles and fuel storage systems world-wide.

A vehicle engine component includes piston, cylinder heads and engine blocks made by aluminum metal, whereas pumps and injectors are often composed of copper and its alloys, and parts composed of stainless steel include fuel filter, valve bodies, nozzle and pump ring [13]. In particular, there is a growing trend to substitute aluminum metal and its alloys for conventional steel and cast irons in vehicles as a result of more stringent requirements for improved fuel economy and emissions [11,14]. Automakers look for ways to reduce a vehicle's weight in order to generate better fuel economy and performance from last decade [15]. Aluminum-based light-weight materials offer great potential for novel engineering applications, particularly when they are optimized to exhibit high strength and yet provide sufficient reliability. The substantial activity in the research fields of high-strength aluminum and it alloys in engineering fields has been seen from last decades [16]. It is reported that aluminum and it alloys are widely used in piston of light-duty diesel engine on the road nowadays, because they are light, manage the heat of combustion well and can be easily mass produced. In addition, counter part of the use of steel piston in transportation engine has some limitations of being heavy (hurting fuel economy), difficult to machine (because the steel is harder than aluminum). These are some reasons that automakers are replacing transportation engines parts made of iron/steels by aluminum and its alloys in recent years. However, it is generally reported that the aluminum and its alloys are more corroded than steels in biofuels and petroleum products $[5,6,8,11,12,17,18]$.

From another point of view, copper and its alloys are generally used for making windings for alternators, starters, ignition coils and heat exchangers owing its good conductive properties and brass is used for tubes in fuel distribution systems, tubing for coolers, electrical connections. In addition, each of the selected copper and its alloys has different corrosion resistance properties in biofuels $[1,4,8,9]$. The copper and copper alloys are generally more susceptible to corrosion compared to iron and aluminum alloys in biofuels $[4,8]$. It was reported that the corrosiveness of the biodiesel depend on the types of materials exposed in it and hence the corrosion rates of steel, aluminum and copper were reported $0.015,0.202$ and 0.586 miles per year, respectively [9]. It was reported that the corrosion rate of copper and bonze was increased with increasing the concentration of biodiesel in its blends [7]. The pitting corrosion on the surface of copper, 
brass and bronze upon exposed in biodiesel was reported in previous research work [1]. It was reported that the copper metal is more susceptible to corrosion compared to aluminum metal and iron alloys in biodiesel [4]. Similarly, it was reported that aluminum and copper were more corroded than mild steel and stainless steel in rapeseed biodiesel [8]. Therefore, in most cases, biodiesel is usually used by blending with petrodiesel. The biodiesel blends are primarily formulated in order to improve the chemical, physical as well as the corrosion resistance properties and to reduce the materials incompatibility and hence thus making it suitable for automotive applications.

In this context, the use of different types of environmental friendly and biocompatibility corrosion inhibitors originated from different parts of plant is currently becoming one of the most common methods for protecting of metallic materials against corrosion in all industrial sectors including petrochemical facilities in the world [19-22]. It was reported a synergistic effect between the different organic molecules present in plant extracts towards enhancing their corrosion inhibition on metals and alloys in varied aggressive environments [23]. Corrosionists have one of the best options to use different types of corrosion inhibitors as an additive in the biofuels to control/prevent their corrosive nature towards various metallic materials [24-28]. It is estimated that about 3.7 billion US dollar is spent for controlling the metallic corrosion in oil and gas industries per year [24]. However, by implementation of existing various corrosion preventing technologies in a proper way, such amounts of corrosion cost can be reduced up to 15-35\% [25]. Within the various corrosion controlling methods/techniques, the use of green inhibitors is becoming one of the best methods to prevent/minimize such corrosion problems.

In general, synthetic organic compounds are commonly used as corrosion inhibitor in different biofuels to reduce their corrosive nature to different metallic materials used in transportation engine parts, fuel storage systems and so on [13, 26-30]. Synthetic organic compounds of ethylenediamine, tert-butylamine and $n$-butylamine have been reported to be effective in the formation of a stable metal oxide as protective layer and thus retarding corrosion of different metallic materials in biodiesel [13], although a very few research works had reported the effects of some plant extracts as a green corrosion-resistant improvers for different metallic materials in biodiesel, bioethanol and their respective blends with petroleum products [11, 24,31,32]. Further studies on the effectiveness of green corrosion inhibitor, obtained from a versatile plant of Vitex negundo leaf extract are projected in this study to decrease the corrosiveness of biodiesel and its blends.

Vitex negundo, called as Chaster tree in English and SIMALI in Nepali and belonging to family Verbenaceae, is a small plant distributed throughout the lower part of Himalayan regions of Nepal and it is used in various purposes as fodder to medicinal values in Nepal [33]. Previous study reported that an aqueous extract of $V$. negundo leaves, which contained of 5-hydroxy-3,6,7,3', $4^{\prime}$-pentamethoxy flavones, possesses antieosinophilic activity, reduces bronchial hyper responsiveness, and be useful in the treatment of asthma, various inflammatory, allergic and immunologic diseases [34]. Similarly, the alcohol 
soluble extracts of $V$. negundo leaves collected from different parts of India had yielded several types of polar organic compounds like phenols, alkaloids, steroids, glycosides, flavonoids and so on from phytochemical studies [35-37]. Anti-inflammatory activity and identification of seven new diterpenes negundoins from different parts of $V$. negundo were reported [38, 39]. On the other hand, it was reported that the methanolic extract of the Nepalese origin $V$. negundo plant leaves contained eight major compounds of negundoside, agnuside, vitegnoside, 7,8-dimethyl herbacetin 3-rhamnoside; 5,3'-dihydroxy-7,8,4'trimethoxy flavanone; 5-hydroxy-3,6,7,3',4'-pentamethoxy flavones; 5,7-dihydroxy-6,4'dimethoxy flavonone and 5-hydroxy-7,4'-dimethoxy flavones [40]. In one pharmacological assessment on the medicinal plants of far-western parts of Nepal, it had pointed out the important uses of the $V$. negundo species for treatment of different diseases by local people [33].

However, it has not yet reported the important aspects of this plant extracts as a corrosion inhibitor for controlling the destructive behavior of different types of fossil and biofuels to different metallic materials used in transportation and storage systems used in Nepal, although the $V$. nigundo extract had used as a corrosions inhibitor for minimizing the corrosion behavior of metals and alloys in other aggressive environments [41, 42]. For examples, the inhibitive performance of $V$. negundo leaf extract on the copper corrosion in nitric acid solution was investigated and the plant extract was reported as efficient to control copper corrosion by inhibiting the cathodic reaction [41]. Moreover, it was pointed out that the corrosion inhibition efficiency for aluminum metal was reported to be increased with increasing of $V$. negundo leaf extract and reached the maximum efficiency of about $73 \%$ at $900 \mathrm{ppm}$ extract concentration and it acted as mixed type inhibitor from potentiodynamic and chemical analysis in alkaline solution [42]. In this circumstances, the main objective of the present research work was to study the corrosion inhibition effect of methanol extract of Vitex negundo plant leaf on aluminum and copper metals in pure biodiesel (B100) synthesized from the waste cooking oil and its $10 \%$ biodiesel blend (B10) with $90 \%$ commercial petrodiesel using corrosion tests, corrosion inhibition and electrochemical measurements at room temperature of $25 \pm 2{ }^{\circ} \mathrm{C}$ in airtight condition.

\section{Materials and methods}

The sample specimens of aluminum and copper metal having the size of about $4 \mathrm{~cm} \times 3 \mathrm{~cm} \times 0.4 \mathrm{~cm}$ were prepared to carry out for static immersion tests, corrosion inhibition mechanism and anodic polarization measurements. The sample surface of each specimen was mechanically polished using 200-1500 grit numbers SiC paper in ethanol, rinsed with acetone and air-dried until the surface exhibited mirror like reflection in order to obtain reproducible results. The pure biodiesel (B100), used in this study was prepared in laboratory from waste cooking oil collected from local market using trans-esterification method described elsewhere [43] and its $10 \%$ blend (B10) with $90 \%$ commercial 
petrodiesel were used as electrolytic solutions in this research work. The methanol extract of Vitex negundo plant leaves was used as green corrosion inhibitor.

The average corrosion rate of aluminum and copper metal specimens in both B100 and B10 in absence and presence 500,1000, 1500 and $2000 \mathrm{ppm}$ of $V$. negundo leaf extract was estimated using weight loss method as given in Equation $1[44,45]$, where $\Delta w, d$ and $A$ are the weight loss $(\mathrm{g})$, density $\left(\mathrm{g} / \mathrm{cm}^{3}\right)$ and area $\left(\mathrm{cm}^{2}\right)$ of the sample coupons, respectively, and $t$ is immersion time in hours.

$$
\text { Corrosion Rate }(\mathrm{mm} / \mathrm{y})=\frac{\Delta w \times 87600}{d \times A \times t}
$$

The $\%$ corrosion inhibition efficiency $\left(I E_{\%}\right)$ and the degree of surface coverage of the inhibitor molecule $(\theta)$ were obtained from weight loss measurement using Equations 2 and 3 , respectively [19], where $C R_{(0)}$ and $C R_{(\text {inh.) }}$ are the corrosion rates in absence and presence of different concentrations of $V$. negundo extract, respectively. It is meaningful for citing here that all the calculations of the surface coverage $(\theta)$ from the corrosion data are based on the assumption that the plant extract used as corrosion inhibitor totally prevents metal dissolution from the covered surfaces of the corroded metals [46]. The corrosion inhibition process was studied using Langmuir adsorption isotherm equation as given in Equation 4 [47, 48], where the $C_{\text {inh. }}$ is the inhibitor concentration and $K_{\text {ads }}$ is the adsorptive equilibrium constant.

$$
\begin{gathered}
I E_{\%}=\frac{C R_{(0)}-C R_{(\mathrm{inh} .)}}{C R_{(0)}} \times 100 \\
\theta=\frac{C R_{(0)}-C R_{(\text {inh. }}}{C R_{(0)}} \\
\frac{C_{\text {inh. }}}{\theta}=\left(\frac{1}{K_{\text {ads }}}\right)+C_{\text {inh. }}
\end{gathered}
$$

The anodic passivity of aluminum and copper metals in B100 and B10 biofuels open to air at $25 \pm 2{ }^{\circ} \mathrm{C}$ in absence and presence of different concentrations of the $V$. negundo extract was studied using a potentiostat/galvanostat (Hokuto Denki A-151 model). The anodic potentiodynamic polarization measurement was carried out at the scan rate of $30 \mathrm{mV}$ per minute for better understanding of the effect of $V$. negundo plant extract as a green corrosion inhibitor. The $0.10 \mathrm{~mol} / \mathrm{L}$ lithium perchlorate salt was added as a supporting electrolyte to both B100 and B10 electrolytes in order to increase their conductivity. The lithium perchlorate was chosen in order to avoid adsorption on the metal surface [49]. In this study, a saturated calomel electrode (SCE), the aluminum or copper sample specimens and graphite rod was used as reference, working and auxiliary electrodes, respectively. 


\section{Results and discussion}

The average corrosion rates of aluminum and copper metal samples were estimated in pure biodiesel (B100), 10\% biodiesel blend (B10) with 90\% commercial petrodiesel and pure commercial petrodiesel (B0), after immersion for different time intervals from 360 hours to 4620 hours at room temperature $\left(25 \pm 2^{\circ} \mathrm{C}\right)$ in air tight condition using weight loss method and the results are summarized in Figure 1. It is observed that the corrosion rate of aluminum metal is decreased more clearly than that of copper metal with immersion time up to 4620 hours in all biofuels and petroleum fuels used in this study. The average corrosion rates of aluminum metal in B100, B10 and B0 were estimated as $1.36 \times 10^{-3}$, $1.01 \times 10^{-3}$ and $0.89 \times 10^{-3} \mathrm{~mm} / \mathrm{y}$, respectively, and of copper metal in B100, B10 and B0 were estimated as $10.21 \times 10^{-3}, 3.34 \times 10^{-3}$ and $0.42 \times 10^{-3} \mathrm{~mm} / \mathrm{y}$, respectively, after immersion for about six and half months at $25 \pm 2^{\circ} \mathrm{C}$ in airtight condition as shown in Figure 1. These results revealed that the commercial petrodiesel is found to be less corrosive in nature than the waste cocking oil biodiesel and its $10 \%$ blend for both aluminum and copper metals at room temperature in airtight condition. In particular, the corrosion rate of copper metal showed significantly (i.e., nearly one order of magnitude) high in biodiesel and its $10 \%$ blend than in $\mathrm{B} 0$.

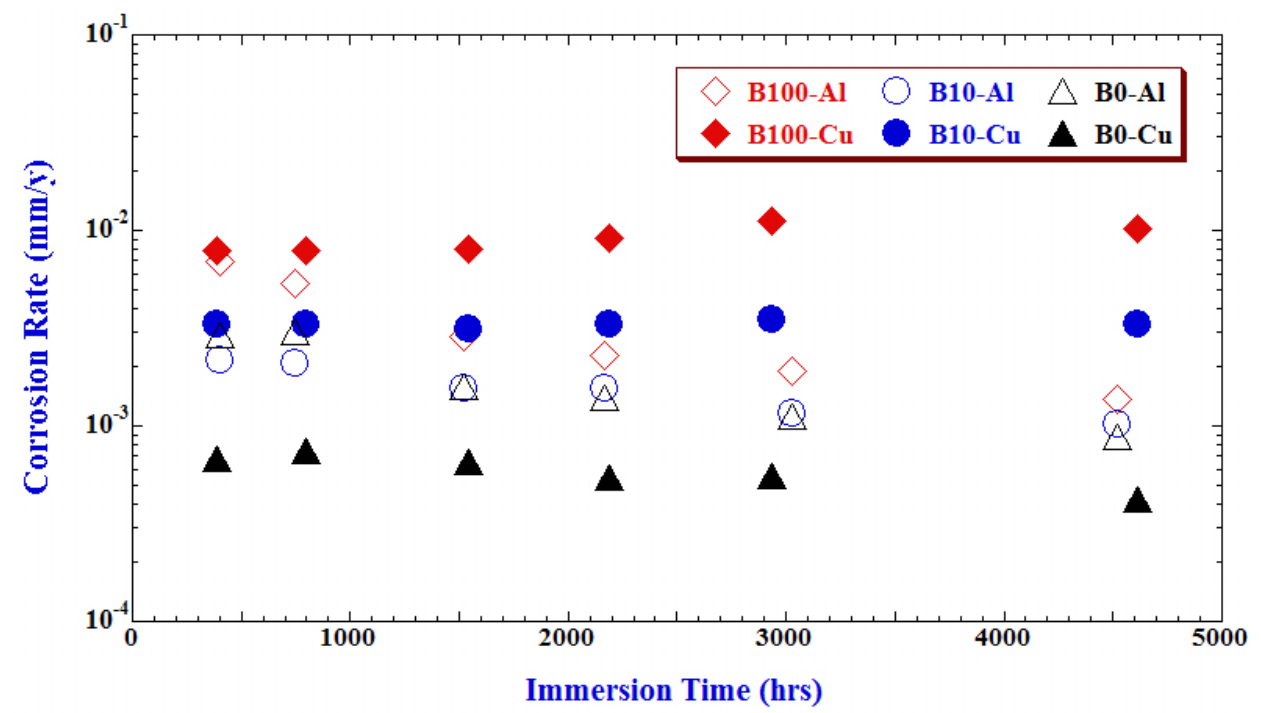

Figure 1. Changes in the corrosion rate of aluminum and copper metals in B100, B10 and B0 at $25 \pm 2^{\circ} \mathrm{C}$ in airtight condition, as a function of immersion time.

In this context, it is very interesting to study the effects of different plant extracts as a green corrosion inhibitor to decrease the corrosive nature of these two biofuels of B100 and B10 for aluminum and copper metals. Hence, the effect of 500, 1000, 1500 and $2000 \mathrm{ppm}$ of $V$. negundo plant extract in both B100 and B10 was further studied to know the corrosion behavior of aluminum and copper metals in these two biofuels after immersion for different time intervals up to about six and half months at $25 \pm 2{ }^{\circ} \mathrm{C}$ in air 
tight condition using corrosion tests, inhibition mechanism and anodic polarization measurements.

The corrosion rates of both aluminum and copper metals are decreased significantly with increasing the immersion time up to about six and half months in B100 without and with additions of 500,1000, 1500 and $2000 \mathrm{ppm} V$. negundo plant extract as a green corrosion inhibitor at $25 \pm 2{ }^{\circ} \mathrm{C}$ in air tight condition as shown in Figures 2(a) and 2(c), respectively. The corrosion resistance properties of these two metals are increased with increasing the concentrations of 500 to $2000 \mathrm{ppm} \mathrm{V}$. negundo plant extract as a green corrosion inhibitor in B100. The similar effect was observed for both aluminum and copper metals in B10 biodiesel blend without and with additions of 500, 1000, 1500 and $2000 \mathrm{ppm}$ green corrosion inhibitor extracted from leaf part of $V$. negundo plant as shown in Figures 2(b) and 2(d), respectively. In particular, the corrosion resistance property of copper metal in B100 with additions of 500-2000 ppm plant extract is found to be nearly 1.5 orders of magnitude higher than in B100 only without corrosion inhibitor as shown in Figure 2(c).
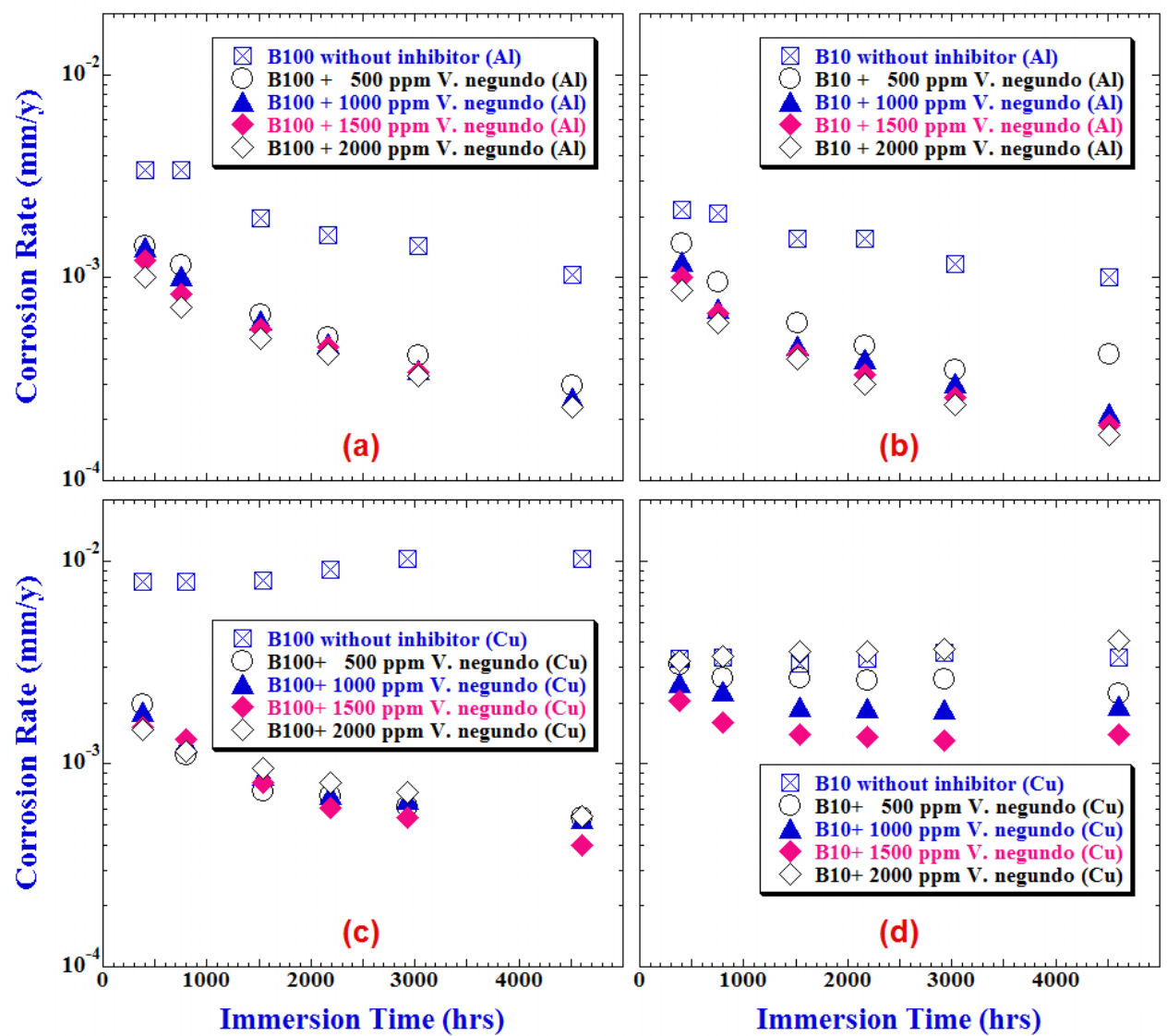

Figure 2. Changes in the corrosion rate of aluminum metal in (a) B100 \& (b) B10 and copper metal in (c) B100 \& (d) B10 without and with different concentrations of $V$. negundo plant extract at $25 \pm 2{ }^{\circ} \mathrm{C}$ in airtight condition, as a function of immersion time. 
Similarly, the corrosion resistance property of aluminum metal in both B100 and B10 biofuels with the additions of 500-2000 ppm V.negundo plant extract is found to be nearly one order of magnitude higher than those in B100 and B10 biofuels only without plant extract as shown in Figures 2(a) and 2(b), respectively. However, the corrosion resistance property of copper metal in B10 with the additions of 500-2000 ppm $V$. negundo plant extract is not significantly high as shown in Figure 2(d). Furthermore, it is clear from Figure 2(d) that the corrosion-resistant of copper metal in 10\% biodiesel blend is improved with the additions of 500 to $1500 \mathrm{ppm}$ leaf extract of $V$. negundo plant and further addition of $2000 \mathrm{ppm}$ plant extract in B10 does not seem to be very beneficial to increase the corrosion resistance property of copper metal in the biodiesel blend of B10. Consequently, it can be said that leaf extract of $V$. negundo plant acts as a significant green inhibitor to control the corrosion of copper metal in pure biodiesel of waste cooking oil at room temperature in airtight condition.

The changes in the corrosion inhibition efficiency of different concentrations of $V$. negundo plant extract for both aluminum and copper metals exposed up to six and half months long in $\mathrm{B} 100$ and $\mathrm{B} 10$ at $25 \pm 2{ }^{\circ} \mathrm{C}$ in airtight condition is shown in Figures 3(a) and 3 (b), respectively. Initially the inhibition efficiency is steeply increased with increasing the concentration of the plant extract up to $500 \mathrm{ppm}$ and the maximum inhibition efficiency of about $96 \%$ and $83 \%$ for copper and aluminum metals, respectively, were obtained at 2000 ppm V. negundo plant extract addition in B100 as shown in Figure 3(a). On the other hand, the inhibition efficiency of the plant extract used in this study for aluminum metal is increased initially with increasing its concentration up to $1000 \mathrm{ppm}$ and shows the maximum inhibition efficiency of about $83 \%$ in B10 with the addition of $2000 \mathrm{ppm}$ plant extract, although the inhibition efficiency of $V$. negundo plant extract for copper metal is increased initially with increasing its concentration up to $1500 \mathrm{ppm}$ and it shows the maximum inhibition efficiency of about $68 \%$ only in B10 with the addition of $1500 \mathrm{ppm}$ plant extract as shown in Figure 3(b).
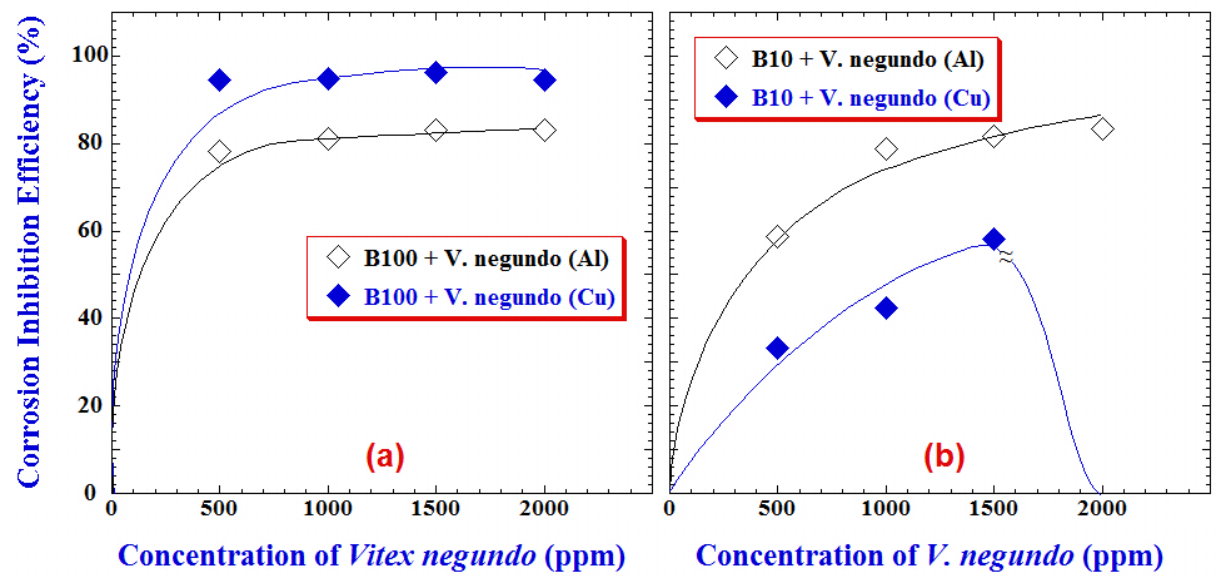

Figure 3. Changes in the corrosion inhibition efficiency for aluminum and copper after exposed for about six and half months in (a) B100 and (b) B10 at $25 \pm 2{ }^{\circ} \mathrm{C}$, as a function of the concentration of $V$. negundo plant extract. 
Such trend of the increase in inhibition efficiencies with the increase of plant extract concentration shows that the inhibition action to both aluminum and copper metals is due to adsorption process. In addition, the trend of the corrosion inhibition activity of the leaf extract of $V$. negundo plant for aluminum and copper metals in B100 and B10 is in the order of $\% I E_{(\mathrm{Cu} \text { in B100) }}>\% I E_{(\mathrm{Al} \text { in B100) }}>\% I E_{(\mathrm{Al} \text { in B10) }}>\% I E_{(\mathrm{Cu} \text { in B10) }}$. Consequently, it can be reasoned out from the observed results of the corrosion inhibition efficiency that the methanolic fraction of the $V$. negundo plant extract can be used as a fuel additives in B100 biofuel to control significantly the corrosion behavior of copper metal and the result is in agreement with the results of corrosion tests as shown above in Figure 2.

The adsorption isotherms are of extreme importance in understanding the mechanism of the corrosion inhibition of metals/alloys by plant extracts as green corrosion inhibitors in corrosive electrolytes [50]. Langmuir adsorption isotherm is one of the simplest models and it describes the molecular interaction between the inhibitor molecules and the active surfaces of the corroded metallic materials based on the assumption that all adsorption sites are equivalent and the particle binding occurs independently from nearby sites being occupied or not $[47,48]$. It also shows the relationship between the ratio of inhibitor concentration to surface coverage $\left(C_{\text {inh }} / \theta\right)$ and the inhibitor concentration $\left(C_{\text {inh }}\right)$ as described above in Equation 4. Figures 4(a) and 4(b) show the relationship between $C_{\mathrm{inh}} / \theta$ and $C_{\text {inh }}$ for aluminum and copper metals in B100 and B10, respectively, in absence and presence of different concentrations of $V$. negundo plant extract. The results clearly depicted that the linear correlation coefficient $\left(R^{2}\right)$ is found to be almost equal to unity in all cases that indicates the adsorption process obeyed Langmuir adsorption isotherm to study the corrosion inhibition mechanism of aluminum and copper metals by $V$. negundo plant extract in $\mathrm{B} 100$ and $\mathrm{B} 10$ at $25 \pm 2{ }^{\circ} \mathrm{C}$ in airtight condition.

Accordingly, the corrosion inhibition mechanism of the methanolic extract of $V$. negundo leaves for both the aluminum and copper metals can be explained by the formation of a stable metal oxide layer formed on the surface of these two metals exposed to biodiesel and it blends with petrodiesel. The oxygen-, nitrogen-, sulfur- and halidesbased organic compounds containing $V$. negundo extract is thus adsorbed on the surfaces of both aluminum and copper metals which prevent their corrosion by forming a barrier layers. It is substantive to cite here that amine-based inhibitors were reported the formation of a corrosion protective layers onto the metal surface by an adsorption phenomena occurs either through metal-nitrogen bonding via $\pi$ - electrons by chemisorptions or with a protonated amine by the formation of a hydrogen bond to the metal surface [51].

An anodic polarization measurement was carried out in B100 and B10 in absence and presence of $V$. negundo plant extract for better understanding of the anodic passivity of aluminum and copper metals at $25 \pm 2{ }^{\circ} \mathrm{C}$ in airtight condition and results are depicted in Figures 5 and 6 . The anodic current density of both aluminum and copper metal is observed lower in B100 than in B10 indicating a more stable passive film is formed on the surface of both the metals in pure biodiesel than its $10 \%$ blend with petrodiesel as shown in 
Figures 5(a) and 5(b). Consequently, it can be said that both aluminum and copper metals are more stable in pure biodiesel than in biodiesel blend at ambient conditions.

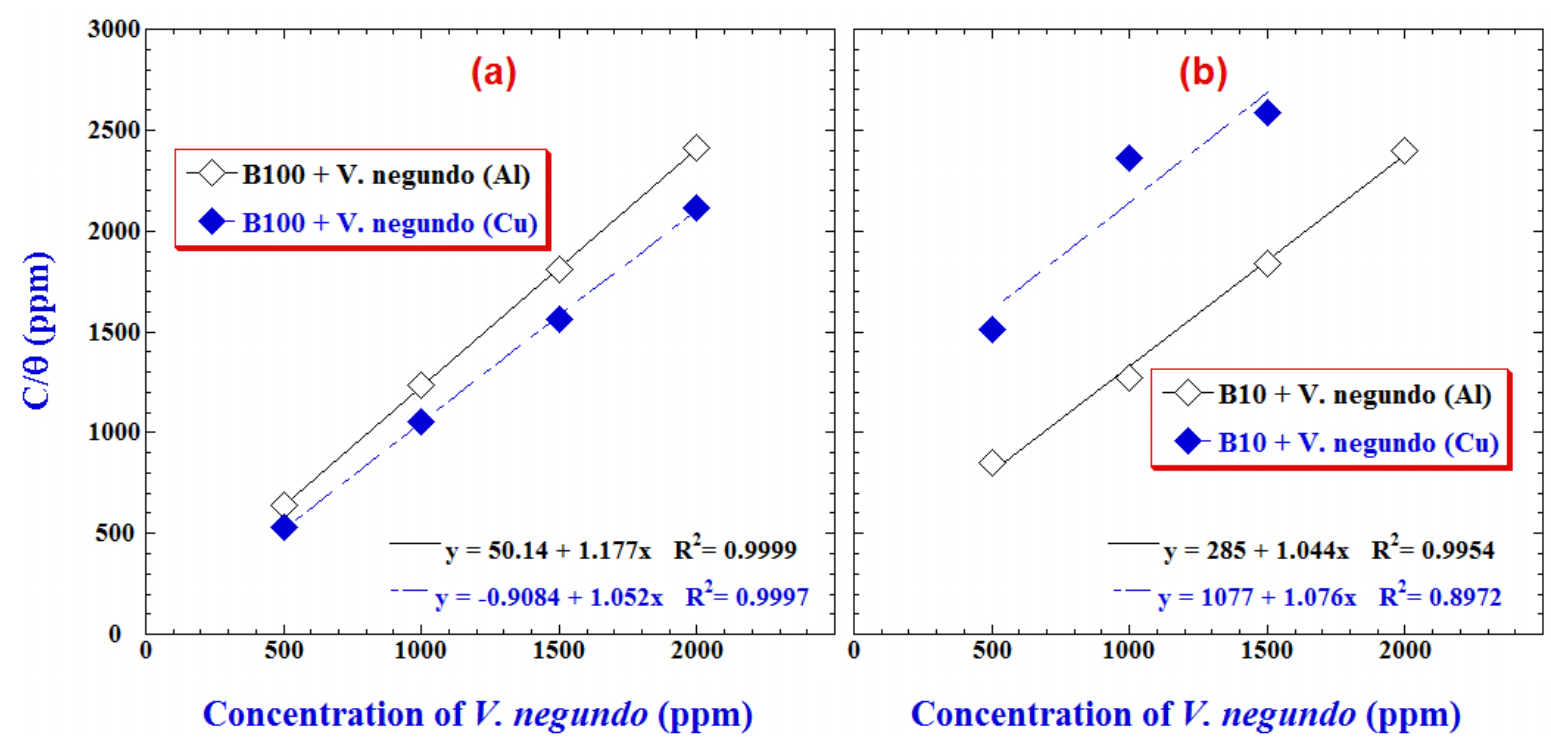

Figure 4. Langmuir adsorption isotherm plot for the corrosion inhibition mechanism on aluminum and copper surface after immersion for about six and half months at $25 \pm 2{ }^{\circ} \mathrm{C}$ in (a) B100 and (b) B10.

An anodic polarization measurement was carried out in B100 and B10 in absence and presence of $V$. negundo plant extract for better understanding of the anodic passivity of aluminum and copper metals at $25 \pm 2{ }^{\circ} \mathrm{C}$ in airtight condition and results are depicted in Figures 5 and 6. The anodic current density of both aluminum and copper metal is observed lower in B100 than in B10 indicating a more stable passive film is formed on the surface of both the metals in pure biodiesel than its $10 \%$ blend with petrodiesel as shown in Figures 5(a) and 5(b). Consequently, it can be said that both aluminum and copper metals are more stable in pure biodiesel than in biodiesel blend at ambient conditions.

Similarly, the effect of different concentrations of $V$. negundo leaf extract on the anodic passivity of aluminum and copper metals was studied and the results are depicted in Figures 6(a) and 6(b). The anodic current density for aluminum metal is decreased with additions of 1000-2000 ppm $V$. negundo plant extract up to anodic polarization about $350 \mathrm{mV}$ vs SCE, although the anodic current density is found to be slightly higher than that of aluminum metal without the plant extract as sown in Figure 6(a). Likewise, the change of the corrosion potential of aluminum metal is found to be shifted to more noble direction with increasing the $V$. negundo plant extract concentrations of $500-1500 \mathrm{ppm}$. Consequently, it can be said that the anodic passivity is enhanced and a stable anodic passive film is formed on the surface of aluminum metal in B100 with the additions of different concentrations of $V$. negundo plant extract as a green corrosion inhibitor. The similar trend is clearly observed for aluminum metal in B10 with the additions of 1000 to $2000 \mathrm{ppm}$ of $V$. negundo plant extract except $500 \mathrm{ppm}$ as sown in Figure 6(b) and 
minimum amount of the anodic current density is obtained for aluminum in B10 with 2000 ppm plant extract. Furthermore, the corrosion potential is sifted to noble direction with additions of $V$. negundo plant extract. These results revealed that the $V$. negundo plant extract acts as an anodic type of corrosion inhibitor to improve the corrosion resistance property of aluminum in both the B100 and B10 biofuels.

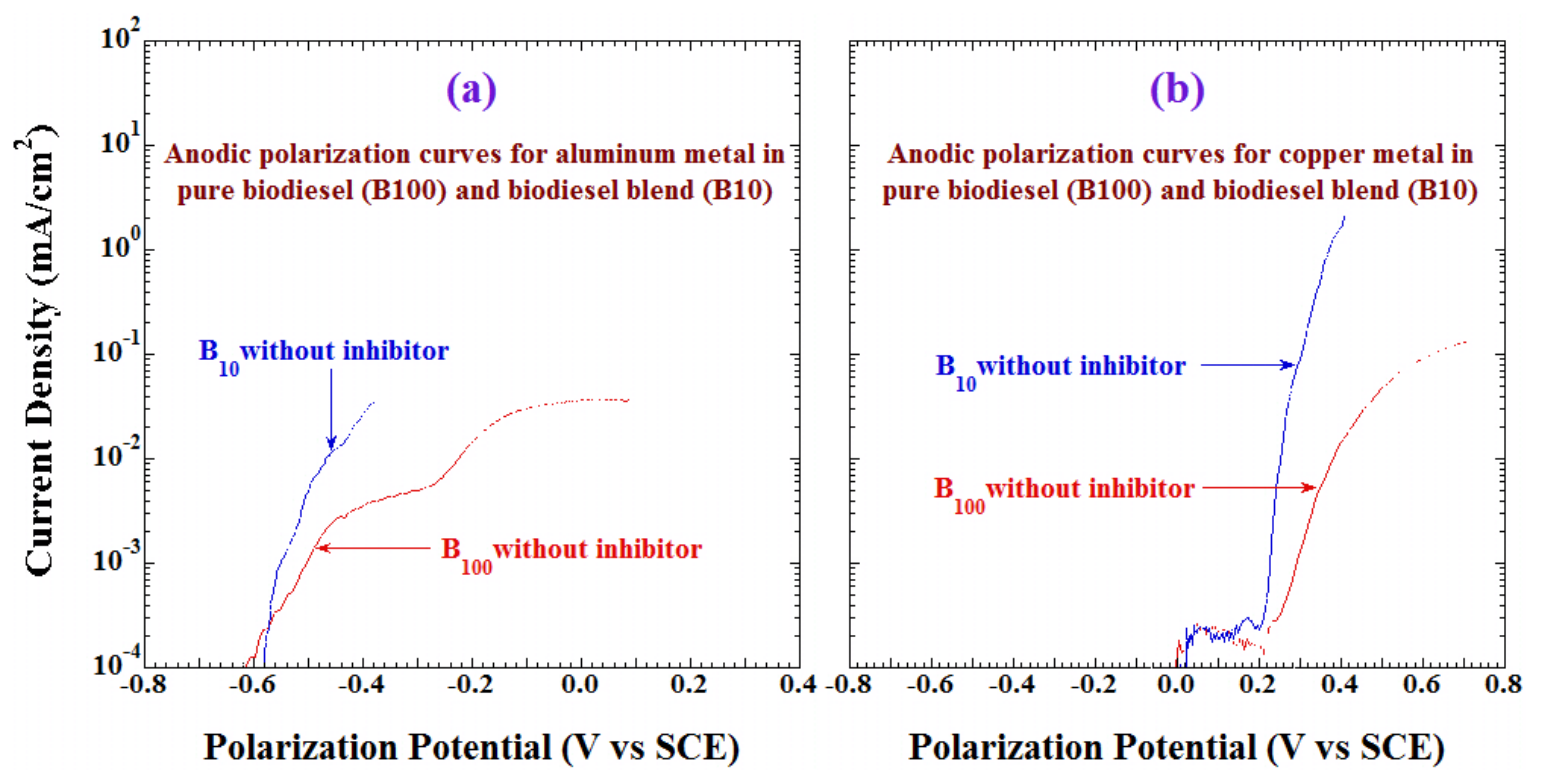

Figure 5. Potentiodynamic anodic polarization curves for (a) aluminum and (b) copper metals in $\mathrm{B} 100$ and $\mathrm{B} 10$ biofuels at $25 \pm 2^{\circ} \mathrm{C}$ in airtight condition.

Similarly, the anodic current density for copper metal in the anodic polarization potential region of -50 to $230 \mathrm{mV}$ vs SCE is found to be almost same in B100 with the additions of 500 to $1000 \mathrm{ppm} V$. negundo plant extract as shown in Figure 6(c). However, the transpassivity potential of the copper metal in B100 is generally decreased with increasing the concentrations of $V$. negundo plant extract. Consequently, it can be said that the anodic passivity of the copper metal is significantly enhanced only to a certain anodic polarization potential and the stability of passive film of copper metal is decreasing with increasing the concentrations of $V$. negundo plant extracts. It is important to cite here that the corrosion rate of the copper metal is found to decrease with increasing the concentrations of $V$. negundo plant extract in B100 as clearly shown above in Figure 2(c). These results disclosed that the plant extract of $V$. negundo acts as a mixed type green corrosion inhibitor for copper in pure biodiesel.

The active-passive and transpassive dissolution of the copper metal is clearly seen in B10 with the addition of $500 \mathrm{ppm} \mathrm{V.negundo} \mathrm{plant} \mathrm{extract,} \mathrm{although} \mathrm{the} \mathrm{copper} \mathrm{metal}$ becomes the passive in the anodic polarization potential regions between about 0 to $220 \mathrm{mV}$ vs SCE in B10 without and with 1000 and $1500 \mathrm{ppm}$ of $V$. negundo plant extract as shown in Figure 6(d). Consequently, it can be said that the copper metal in 10\% biodiesel blend with the addition of only $500 \mathrm{ppm}$ of $V$. negundo plant extract is not 
sufficient to form the anodic passive film on the surface of copper, although the corrosion rate of the copper metal in this condition was found to improve significantly as shown above in Figure 2(d). On the other hand, there is no regular trend of the change of the corrosion potential with concentration of the $V$. negundo plant extract additions in B10. The corrosion potential of the copper in B10 with $V$. negundo plant extract is located between the potentials of copper metal in absence and presence of $500 \mathrm{ppm}$ extract. The anodic current density of the copper metal in B10 with $2000 \mathrm{ppm} \mathrm{V.} \mathrm{negundo} \mathrm{plant} \mathrm{extract}$ is significantly high as comparison with others as shown in Figure 6(d). These results revealed that the plant extract of $V$. negundo acts as a mixed type of green corrosion inhibitor to improve the corrosion resistance property of copper in $10 \%$ biodiesel blend with $90 \%$ petrodiesel.
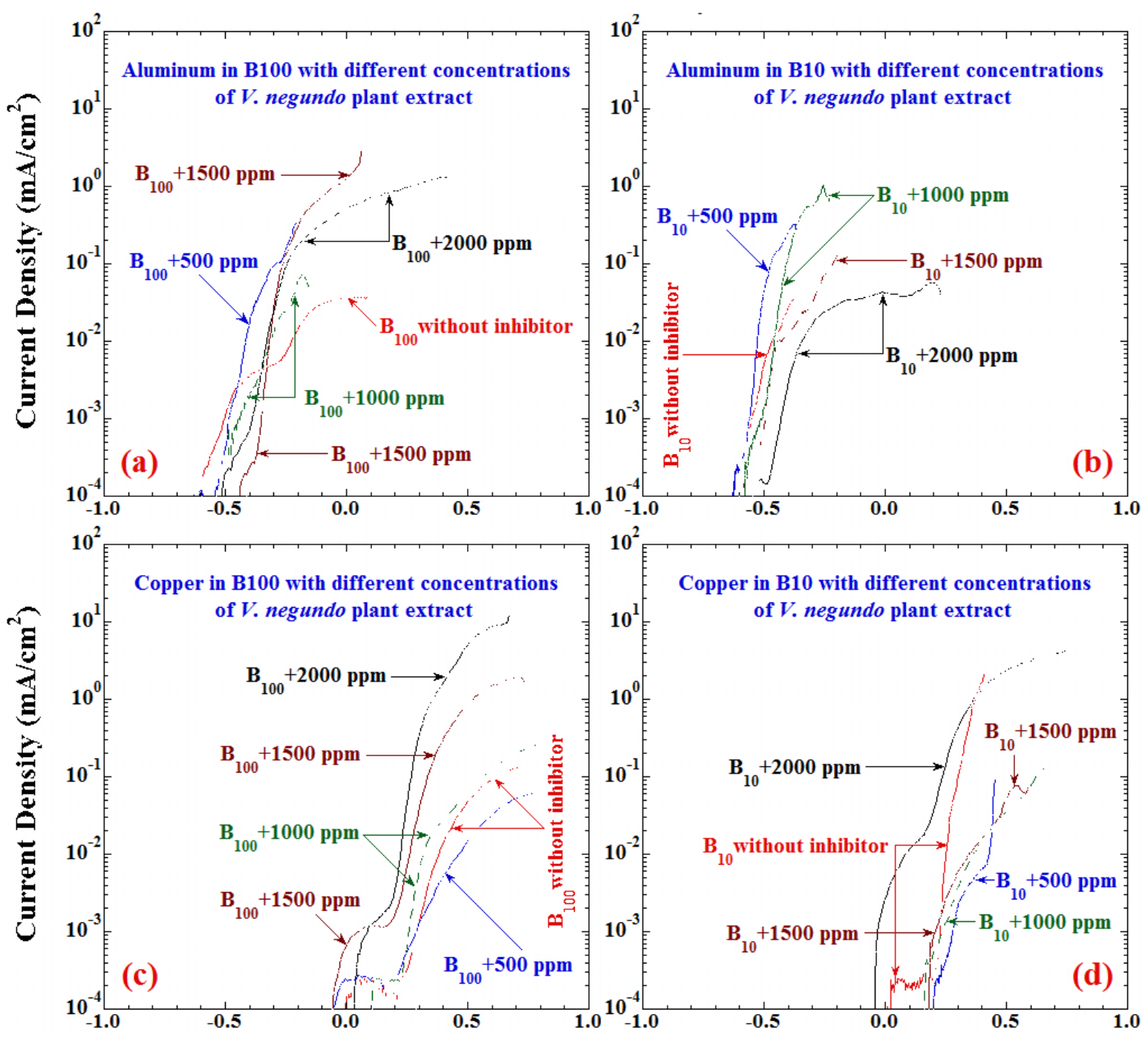

Polarization Potential (V vs SCE)

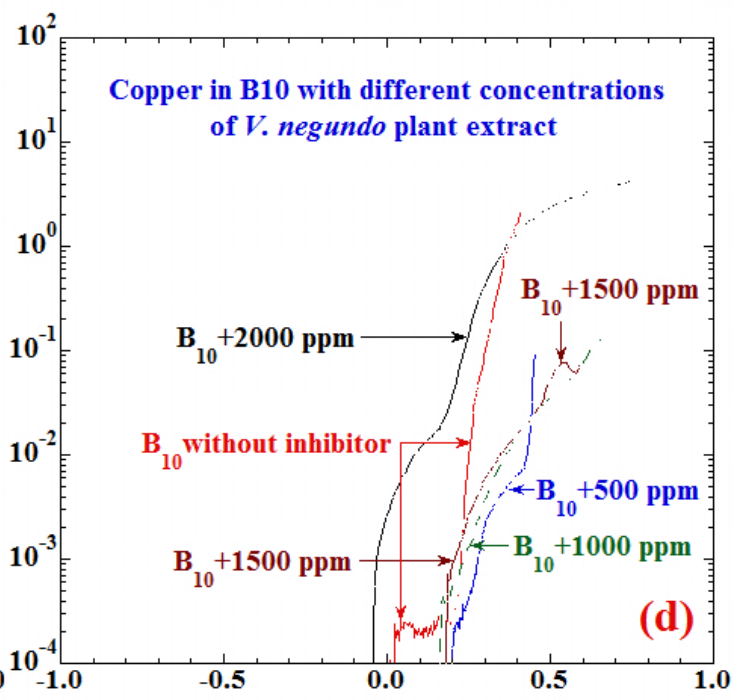

Polarization Potential (V vs SCE)

Figure 6. Potentiodynamic anodic polarization curves for aluminum in (a) B100 and (b) B10, and for copper in (c) B100 and (d) B10 with the additions of different concentrations of Vitex negundo plant extract at $25 \pm 2^{\circ} \mathrm{C}$ open to air. 


\section{Conclusions}

The methanol extract of Vitex negundo plant leaves was used as a green corrosion inhibitor in this study to control the corrosion of metallic materials of aluminum and copper metals in pure biodiesel (produced from waste cooking oil) and its $10 \%$ blend with $90 \%$ petrodiesel at $25 \pm 2{ }^{\circ} \mathrm{C}$ in airtight condition using immersion tests, inhibition processes, corrosion potential and anodic polarization measurements. The following conclusions could be drawn from this study:

1. Commercial petrodiesel is found to be less corrosive in nature than the waste cocking oil biodiesel and its $10 \%$ blend for both aluminum and copper metals at ambient temperature.

2. Methanolic extract of Vitex negundo leaves can be used as green corrosion inhibitor to increase the corrosion resistance properties of aluminum and copper metals in both B100 and B10 at ambient temperature.

3. The trend of the corrosion inhibition activity of the leaf extract of $V$. negundo for aluminum and copper metals in B100 and B10 is in the order of $\% I E_{(\mathrm{Cu} \text { in B100) }}>\% I E_{(\mathrm{Al} \text { in }}$ B100) $>\% I E_{(\mathrm{Al} \text { in B10) }}>\% I E_{(\mathrm{Cu} \text { in B10) }}$.

4. The $V$. negundo extract can be used as a fuel additives in B100 to control significantly the corrosion behavior of copper metal.

5. Adsorption process obeyed Langmuir adsorption isotherm to study the corrosion inhibition phenomena of aluminum and copper metals by $V$. negundo plant extract in B100 and B10 at ambient temperature.

6. It can be said that both aluminum and copper metals are more stable in pure biodiesel than in biodiesel blend at ambient conditions from polarization measurements.

7. The $V$. negundo extract acts as an anodic type of corrosion inhibitor to improve the corrosion resistance property of aluminum in both the B100 and B10 biofuels, while it acts as a mixed type green corrosion inhibitor for copper in both the B100 and B10 biofuels.

\section{Acknowledgement}

The Nepal Academy of Science and Technology (NAST), Khumaltar, Lalitpur of Nepal is highly acknowledged for providing the NAST Research Grant No.: 2-2075/76 to conduct this research work in Central Department of Chemistry, Tribhuvan University.

\section{References}

1. A.S.M.A. Haseeb, M.A. Fazal, M.I. Jahirul and H.H. Masjuki, Fuel, 2011, 90, 922931. doi: $\underline{\text { 10.1016/j.fuel.2010.10.042 }}$

2. M. Mofijur, M.G. Rasul, N.M.S. Hassan, M.M.K. Khan and H.K. Rashedul, in: Application of Thermo-fluid Processes in Energy Systems, Green Energy and Technology, Eds.: M.M.K. Khan, A. Chaudhary and N.M.S. Hassan, 2018, 35-56. 
3. S. Dharma, H.C. Ong, H.H. Masjuki, A.H. Sebayang and A.S. Silitonga, Energy Convers. Manage., 2016, 128, 66-81. doi: 10.1016/j.enconman.2016.08.072

4. K.A. Sorate and P.V. Bhale, Renewable Sustainable Energy Rev., 2015, 41, 777-798. doi: 10.1016/j.rser.2014.08.079

5. W. Aperador, J. Caballero-Gómez and A. Delgado, Int. J. Electrochem. Sci., 2013, 8, no. 5, 6154-6161.

6. L. Cao, G. Frankel and N. Sridhar, Electrochim. Acta, 2013, 104, 255-266. doi: 10.1016/j.electacta.2013.04.112

7. A.S.M.A. Haseeb, H.H. Masjuki, L.J. Ann and M.A. Fazal, Fuel Process. Technol., 2010, 91, no. 3, 329-334. doi: 10.1016/j.fuproc.2009.11.004

8. E. Hu, Y. Xu, X. Hu, L. Pan and S. Jiang, Renewable Energy, 2012, 37, no. 1, 371378. doi: 10.1016/j.renene.2011.07.010

9. M.A. Fazal, A.S.M.A. Haseeb and H.H. Masjuki, Corros. Sci., 2013, 67, 50-59. doi: 10.1016/j.corsci.2012.10.006

10. V.R. Surisetty, A.K. Dalai and J. Kozinski, Appl. Catal., A, 2011, 404, no. 1-2, 1-11. doi: $10.1016 /$ j.apcata.2011.07.021

11. Y.H. Yoo, I.J. Park, J.G. Kim, D.H. Kwak and W.S. Ji, Fuel, 2011, 90, no. 3, 12081214. doi: $10.1016 /$ i.fuel.2010.10.058

12. B. Jones, G. Mead, P. Steevens and M. Timanus, The Effect of E20 on Metals Used in Automotive Fuel System Components, Minnesota Department of Agriculture, Report No.: 2-22-2008, St. Paul, 2008.

13. B. Singh, J. Korstad and Y.C. Sharma, Renewable Sustainable Energy Rev., 2012, 16, no. 5, 3401-3408. doi: 10.1016/j.rser.2012.02.042

14. G.S. Cole and A.M. Sherman, Mater. Charact., 1995, 35, no. 1, 3-9. doi: 10.1016/1044-5803(95)00063-1

15. P.E. George, Top 10 Improvements in Engine Design, 16 May 2011, https://auto.howstuffworks.com/10-improvements-in-engine-design.htm, 7 September 2018.

16. M.F.-X. Wagner, Metals, 2018, 8, no. 4, 260. doi: $10.3390 /$ met 8040260

17. E.E. Oguzie, G.N. Onuoha and E.N. Ejike, Pigm. Resin Technol., 2007, 36, no. 1, 4449. doi: $10.1108 / 03699420710718751$

18. A.M. Al-Turkustani, S.T. Arab and R.H. Al-Dahiri, Mod. Appl. Sci., 2010, 4, no. 5, 105-124. doi: $10.5539 /$ mas.v4n5p105

19. M. Rana, S. Joshi and J. Bhattarai, Asian J. Chem., 2017, 29, 1130-1134. doi: 10.14233/ajchem.2017.20449

20. C.O. Akalezi, C.E. Ogukwe, E.A. Ejele and E.E. Oguzie, Int. J. Corros. Scale Inhib., 2016, 5, no. 3, 232-247. doi: 10.17675/2305-6894-2016-5-3-4

21. S. Bouazama, J. Costat, J.M. Desjobertb, A. BenAli, A. Guenbour and M. Tabyaoui, Int. J. Corros. Scale Inhib., 2019, 8, no. 1, 25-41. doi: 10.17675/2305-6894-2019-8-1-3 
22. H.I. Al-Itawi, G.M. Al-Mazaideh, A.E. Al-Rawajfeh, A.M. Al-Ma'abreh and A. Marashdeh, Int. J. Corros. Scale Inhib., 2019, 8, no. 2, 199-211. doi: 10.17675/2305-6894-2019-8-2-3

23. V.I. Vorobyova, O. Chygyrynets, M. Skiba, I. Kurmakova and O. Bondar, Int. J. Corros. Scale Inhib., 2017, 6, no. 4, 485-503. doi: 10.17675/2305-6894-2017-6-4-8

24. B.M. Miksic, A.Y. Furman and M.A. Kharshan, Proceedings of Corrosion Conference and Expo-2009, Paper no. 09573, NACE International, Houston, 2009, 1-9.

25. V.I. Vorobyova, M.I. Skiba, A.S. Shakun and S.V. Nahirniak, Int. J. Corros. Scale Inhib., 2019, 8, no. 2, 150-178. doi: 10.17675/2305-6894-2019-8-2-1

26. M.A. Fazal, A.S.M.A. Haseeb and H.H. Masjuki, Fuel Process. Technol., 2011, 92, no. 11, 2154-2159. doi: $10.1016 /$ j.fuproc.2011.06.012

27. E.S. Almeida, F.M. Portela, R.M.F. Sousa, D. Daniel, M.G.H. Terrones and E.M. Richter, Fuel, 2011, 90, no. 11, 3480-3484. doi: 10.1016/j.fuel.2011.06.056

28. M.A. Deyab, Corros. Sci., 2014, 80, 359-365. doi: 10.1016/j.corsci.2013.11.056

29. M. Finšgar and I. Milošev, Corros. Sci., 2010, 52, no. 9, 2737-2749. doi: 10.1016/j.corsci.2010.05.002

30. J. Hancsoik, M. Bubailik, A. Beck and J. Baladincz, Chem. Eng. Res. Des., 2008, 86, no. 7, 793-799. doi: $10.1016 /$ j.cherd.2008.03.011

31. K. Amgain, B.N. Subedi, S. Joshi and J. Bhattarai, Proceedings of CORCON-2018, Paper No.: PP19, NACE International-Gateway of India Section (NIGIS), Jaipur, India, 2018, 1-11.

32. P. Katuwal, K.R. Gaire, and J. Bhattarai, Proceedings of CORCON-2018, Paper No.: MCI-35, NACE International-Gateway of India Section (NIGIS), Jaipur, India, 2018, $1-9$.

33. R.M. Kunwar, K.P. Shrestha and R.W. Bussmann, J. Ethnobiol. Ethnomed., 2010, 6, no. 35, 1-18. doi: 10.1186/1746-4269-6-35

34. J.I. Patel and S.S. Deshpande, Int. J. Nutr., Pharmacol., Neurol. Dis., 2013, 3, no. 2, 135-141. doi: $10.4103 / 2231-0738.112839$

35. B. Sathiamoorthy, P. Gupta, M. Kumar, A.K. Chaturvedi, P.K. Shukla and R. Mauryaa, Bioorg. Med. Chem. Lett., 2007, 17, no. 1, 239-242. doi: 10.1016/j.bmcl.2006.09.051

36. P.K. Dutta, U.S. Chowdhury, A.K. Chakravarty, B. Achari and S.C. Pakrashi, Tetrahedron, 1983, 39, no. 19, 3067-3072. doi: 10.1016/S0040-4020(01)91547-9

37. V. Singh, R. Dayal and J.P. Bartley, Planta Med., 1999, 65, no. 6, 580-582. doi: 10.1055/s-2006-960832

38. C.-J. Zheng, B.-K. Huang, Y. Wang, Q. Ye, T. Han, Q.-Y. Zhang, H. Zhang and L.P. Qin, Bioorg. Med. Chem., 2010, 18, no. 1, 175-181. doi: 10.1016/j.bmc.2009.11.004

39. J. Chen, C.-L. Fan, Y. Wang and W.-C. Ye, Chinese J. Nat. Med. (Zhongguo Tianran Yaowu), 2014, 12, no. 3, 218-221. doi: 10.1016/S1875-5364(14)60036-4

40. L.N. Gautam, S.L. Shrestha, P. Wagle and B.M. Tamrakar, Scientific World, 2008, 6, no. 6, 27-32. doi: $10.3126 /$ sw.v6i6.2630 
41. Savita, P. Mourya, N. Chaubey, V. K. Singh and M. M. Singh, Metall. Mater. Trans. $B, 2016,47$, no. 1, 47-57. doi: 10.1007/s11663-015-0488-6

42. A. Sirajunnisa, M.I. Fazal Mohamed and A. Subramania, J. Chem. Pharm. Res., 2014, 6, no. 1, 580-588. http://www.jocpr.com/archive/jocpr-volume-6-issue-1-year-2014.html

43. A. Yildirim and M. Cetin, Corros. Sci., 2008, 50, no. 1, 155-165. doi: 10.1016/j.corsci.2007.06.015

44. R. Guzatto, D. Defferrari, Q.B. Reiznautt, I.R. Cadore and D. Samios, Fuel, 2012, 92, no. 1, 197-203. doi: 10.1016/j.fuel.2011.08.010

45. J. Bhattarai, Frontiers of Corrosion Science, $1^{\text {st }}$ Ed., Kshitiz Publisher, Kirtipur, Kathmandu, 2010, 304.

46. Yu.I. Kuznetsov, N.N. Andreev and S.S. Vesely, Int. J. Corros. Scale Inhib., 2015, 4, no. 2, 108-109.

47. I. Langmuir, J. Am. Chem. Soc., 1916, 38, no. 11, 2221-2295. doi: $\underline{10.1021 / \mathrm{ja} 02268 \mathrm{a} 002}$

48. I. Langmuir, J. Franklin Inst., 1917, 183, no. 1, 102-105. doi: 10.1016/S00160032(17)90938-X

49. M.A. Deyab, J. Taiwan Inst. Chem. Eng., 2016, 58, 536-541. doi: 10.1016/j.jtice.2015.06.021

50. A.K. Satapathy, G. Gunasekaran, S.C. Sahoo, K. Amit and P.V. Rodrigues, Corros. Sci., 2009, 51, no. 12, 2848-2856. doi: 10.1016/j.corsci.2009.08.016

51. P. Li, J.Y. Lin, K.L. Tan and J.Y. Lee, Electrochim. Acta, 1997, 42, no. 4, 605-615. doi: $\underline{10.1016 / \mathrm{S} 0013-4686(96) 00205-8}$ 